\title{
From Ugi Multicomponent Reaction to Linkers for Bioconjugation
}

Iván Ramos-Tomillero, Gema Pérez-Chacon, Beatriz Somovilla-Crespo, Francisco Sánchez-Madrid, Carmen Cuevas, Juan Manuel Zapata, Juan Manuel Domínguez, Hortensia Rodríguez,* and Fernando Albericio*

Cite This: ACS Omega 2020, 5, 7424-7431

Read Online

山lll Metrics \& More

回 Article Recommendations

Supporting Information

ABSTRACT: Bioconjugation is a key approach for the development of novel molecular entities with clinical applications. The biocompatibility and specificity of biomolecules such as peptides, proteins, and antibodies make these macromolecules ideal carriers for selective targeted therapies. In this context, there is a need to develop new molecular units that cover the requirements of the next generation of targeted pharmaceuticals. Here, we present the design and development of a versatile and stable linker based on a $\mathrm{N}$-alkylated $\alpha, \alpha$-dialkyl dipeptide for bioconjugation, with a particular focus on antibody-drug conjugates (ADCs). Starting with the well-known Ugi multicomponent reaction, the convenient chemical modification of the prepared adducts allowed us the obtention of versatile bifunctional linkers for bioconjugation. A conjugation strategy was tested to demonstrate the efficiency of the linker. In addition, a novel cytotoxic anti-HER2 ADC was prepared using the Ugi-linker approach.

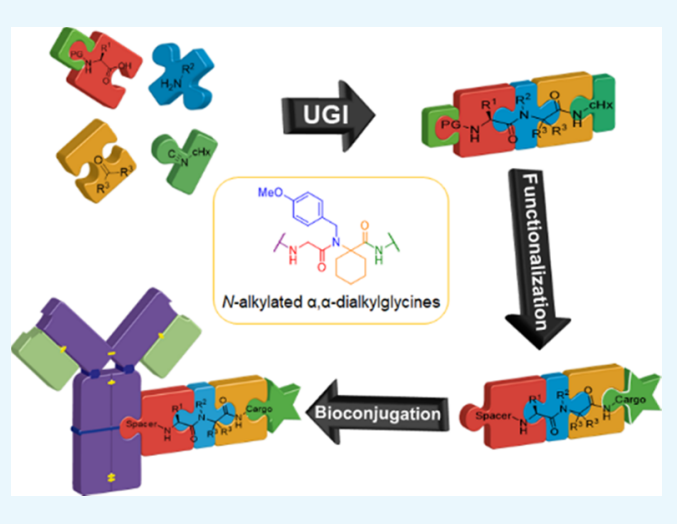

\section{INTRODUCTION}

The development of bioconjugation in recent years spans a broad range of bioconjugates, including biomolecules such as peptides, oligonucleotides, proteins, and antibodies, for biomedical applications. Due to the high potential of bioconjugates as medical treatments, the development of new methodologies that allow the synthesis of novel bioentities is desirable. $^{1,2}$

Regarding antibody-drug conjugates (ADCs), considerable effort by the academic and industrial sectors has been channeled into designing antibodies armed with drugs, cytokines, toxins, and radionuclides, all of them with applications in cancer therapy. ${ }^{3}$ The possibility of combining the favorable binding properties of monoclonal antibodies (mAbs) with the biocidal activities of potent cytotoxic agents promises to increase the therapeutic indexes of these antibodies. ${ }^{4}$ At present, only four ADC products, namely, Adcetris, ${ }^{5}$ Kadcyla, ${ }^{6}$ Besponsa, ${ }^{7}$ and Mylotarg, ${ }^{8}$ have been approved for the treatment of certain types of cancer.

A growing number of parameters can be engineered into novel ADCs, including drug potency, targeting, and also appropriate linker selection. The linker is the most versatile aspect of the $\mathrm{ADC}$ as it contains the reactive group that governs the conjugation chemistry and serves as a chemical spacer that physically connects the drug payload to the antibody. The linker or handle can be modified in various ways to influence drug/linker characteristics (e.g., solubility) and $\mathrm{ADC}$ properties (e.g., potency, pharmacokinetics, therapeutic index, and efficacy in multidrug-resistant cells). ${ }^{9}$
Linkers can be subdivided into two categories: cleavable and non-cleavable. The acidic environment and proteases found in lysosomes and the reductive environment of the cytoplasm are some of the intracellular features exploited for drug release. Examples of cleavable linkers are those based on hydrazones, ${ }^{10}$ disulfides, ${ }^{11}$ or based on an enzymatically cleavable peptidic scaffold. Indeed, peptides can combine both systemic stability and rapid release of the drug inside the target cell. Optimized dipeptide-based linkers, such as those carrying the valinecitrulline sequence, ${ }^{12}$ have shown promising results in terms of specificity and toxicity when compared to other labile linkers. As a result, the valine-citrulline platform is used for Adcetris and for several ADCs in clinical trials. ${ }^{13}$

In contrast, for non-cleavable linkers, it is assumed that the release of the drug takes place after internalization of the ADC in the target cell, which is followed by lysosomal degradation of the antibody to the amino acid level. ${ }^{14}$ The bifunctional crosslinker succinimidyl 4-( $\mathrm{N}$-maleimidomethyl)cyclohexane-1-carboxylate is one of the most commonly used non-cleavable linkers in bioconjugation. ${ }^{15,16}$ The choice of linker is often target- and drug-dependent as intracellular processes contribute to the generation of the fully active drug.

Received: January 8, 2020

Accepted: February 14, 2020

Published: March 23, 2020 
Scheme 1. Ugi Four-Component Reaction To Yield N-Alkylated $\alpha, \alpha$-Dialkylglycines (5a-n) (Yield in Brackets) Followed by C-Terminal Acidolysis. Compound5o Was Isolated as a By-Product of the Ugi Reaction with Isatin (See the Supporting Information). Mmt: 4-Monomethoxytrityl, Fmoc: 9-Fluorenylmethoxycarbonyl, Cbz: Carboxybenzyl, cHx: Cyclohexyl
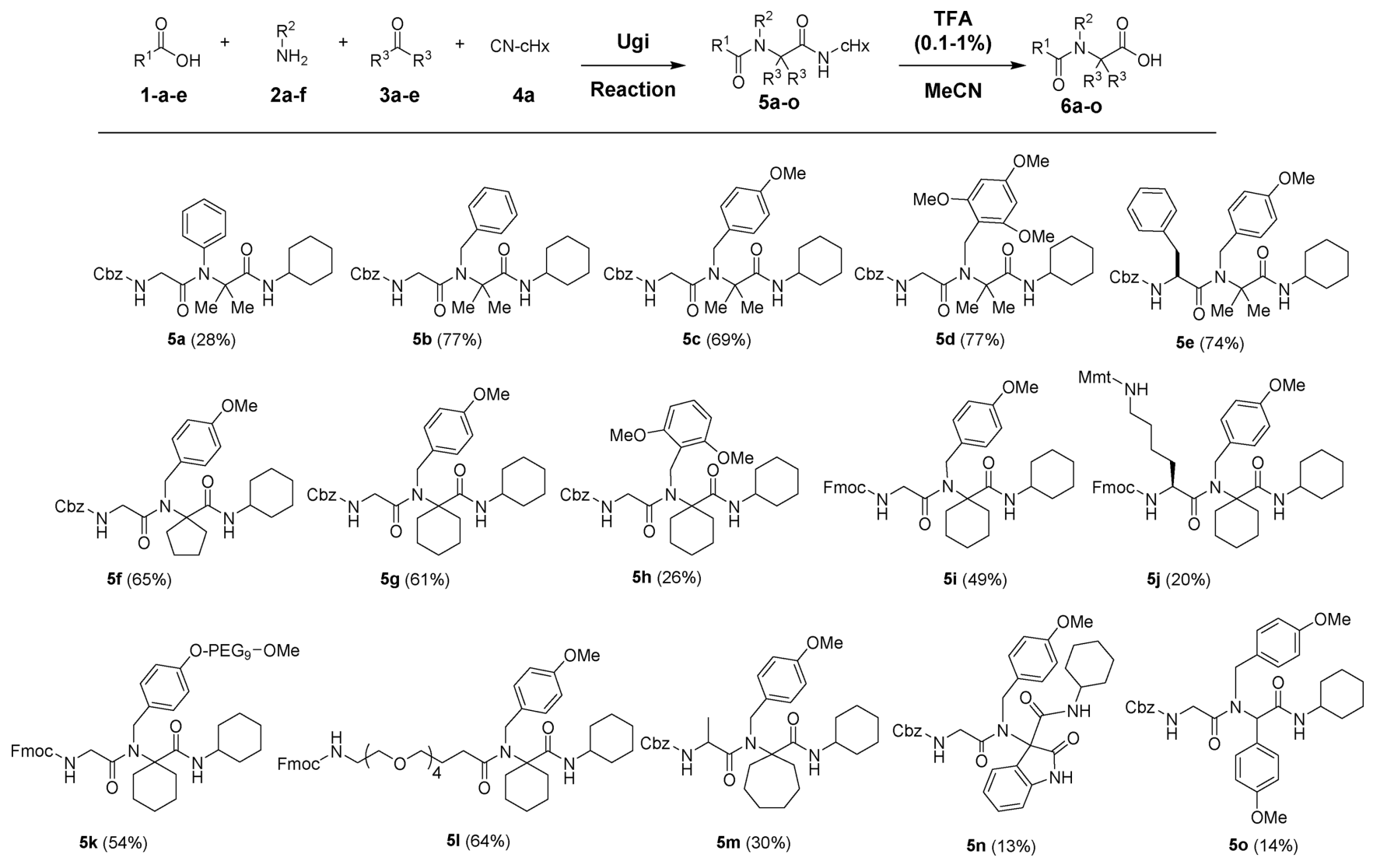

Scheme 2. Bifunctionalization of Ugi Linkers and Activation with $\mathrm{N}$-Hydroxysuccinimide (HOSu) for Bioconjugation. Reaction (a): One-Pot Cbz Hydrogenolysis and Amine Acylation with Diglycolic Anhydride (9) for Compounds8a-c. Reaction (b): Simultaneous Fmoc Group Elimination and Resultant Amine Acylation with 9 for Compounds8d and 8e. See the Supporting Information for Structures and Reaction Yields

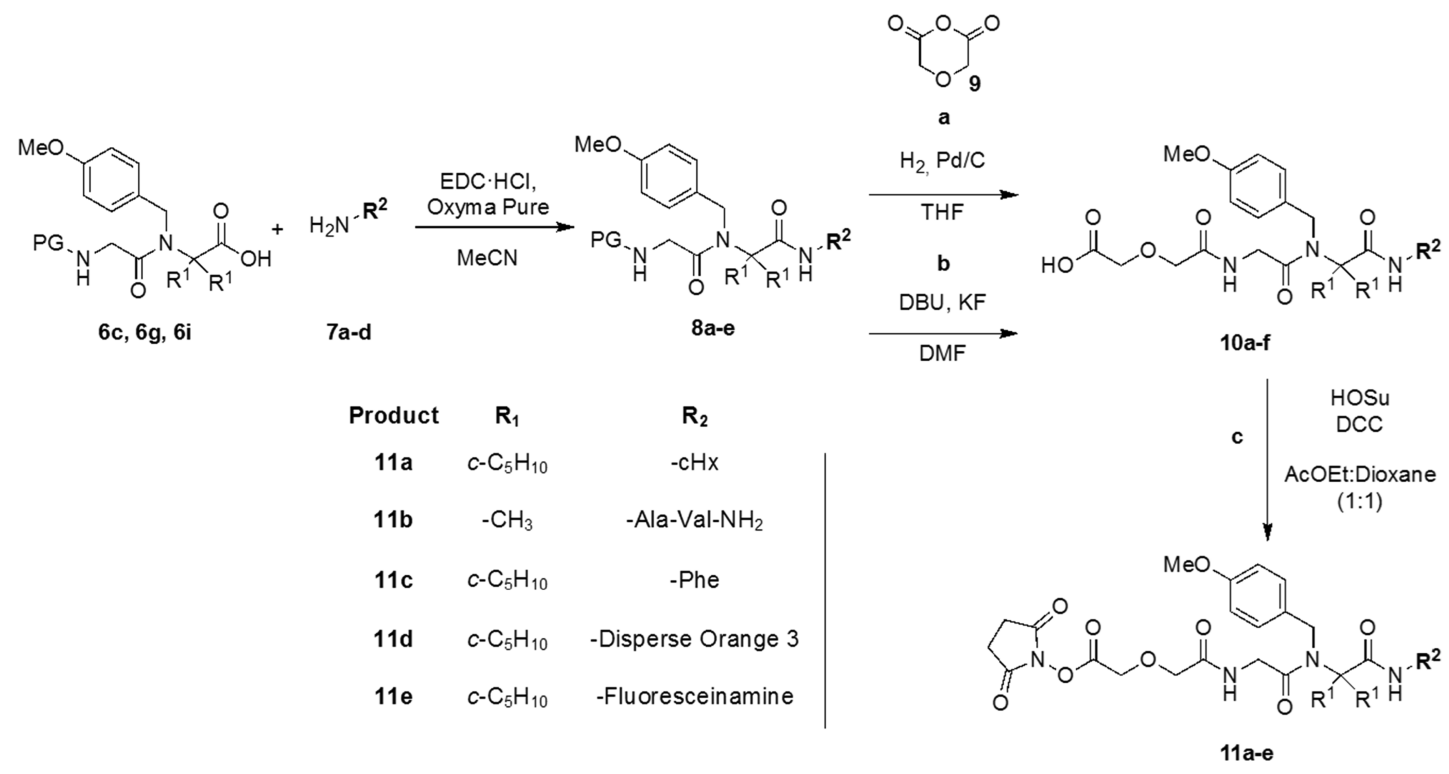

The classical Ugi reaction is a four-component coupling reaction (U-4CR) between an amine, a carbonyl compound (aldehyde or ketone), a carboxylic acid, and isocyanide, which yield a $\mathrm{N}$-alkylated $\alpha, \alpha$-dialkylglycine when ketone is used as the carbonyl compound. ${ }^{17}$ This $4-\mathrm{CR}$ is one of the most important isocyanide-based multicomponent reactions to access peptide-like structures. It has been widely used in modern synthetic chemistry ${ }^{18-24}$ and tentatively used for 
Scheme 3. Lysine-Mediated Bioconjugation with the ActivatedN-Hydroxysuccinic Ester Ugi Adducts to (A) Trastuzumab Pentapeptide, (B) BSA, and (C) Anti-CD4

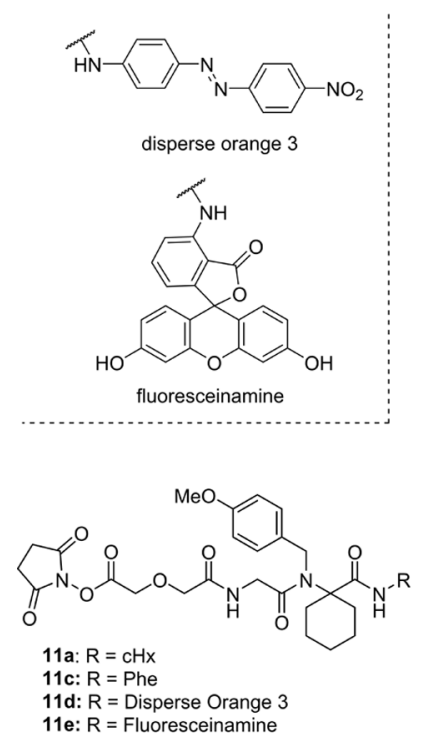

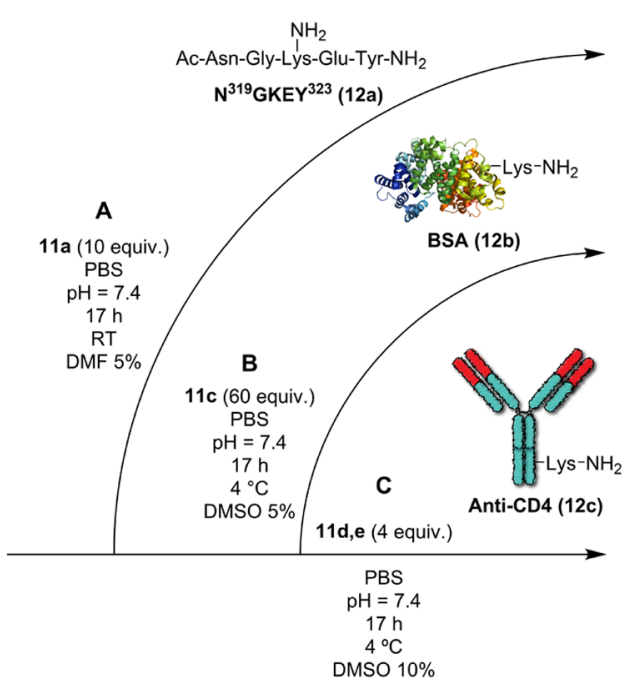

direct bioconjugation. ${ }^{18,25-28}$ In this regard and given the stability that $\mathrm{N}$-alkylated $\alpha, \alpha$-dialkylglycines (Ugi adducts) confer to the peptidic scaffold, our attention was drawn to Ugi adducts as linkers for bioconjugation.

Here, we report the design of an efficient and robust strategy to synthesize and apply trialkylglycine derivatives (Ugi adducts) as versatile linkers for bioconjugation.

\section{RESULTS AND DISCUSSION}

Synthesis of N-Alkylated $\boldsymbol{\alpha}, \boldsymbol{\alpha}$-Dialkyl Glycines. The starting point for the general strategy was focused on the synthesis of trialkylglycine derivatives. To this end, we performed a one-pot synthesis, under Ugi conditions, of a small library of 1,4-dicarbonylic compounds based on $\alpha, \alpha$ dialkylglycines (Ugi adducts, Scheme 1), through the condensation of a carboxylic acid, a primary amine, a ketone, and cyclohexyl isocyanide. In this regard, all the Ugi reactions furnished the desired products $\mathbf{5 a}-\mathbf{n}$ in moderate to high yields and without evidence of amino acid racemization for compounds $5 \mathbf{e}$ and $\mathbf{5 j}$. Compound $\mathbf{5 0}$ was isolated as a byproduct of the Ugi reaction with isatin $(\mathbf{5 n})$.

All Ugi derivatives were subjected to a C-terminal amide acidolysis with trifluoroacetic acid (TFA) solutions. As expected, the rate of acidolysis in the 1,4-dicarbonyl systems depends of the $\mathrm{N}$-alkyl group and of the dialkylic substituents. Thus, the introduction of cyclic compounds into the dipeptidic scaffold forced the approximation of the central carbonyl group to the C-terminal amide by an angle reduction, and consequently, the acidolysis took place faster than with the acyclic compounds. Although most of the corresponding carboxylic acids were obtained from fast $(\mathbf{5 d}, \mathbf{5 i}$, and $\mathbf{5 m})$ to extremely slow (5a or 5o) reaction times, only $6 \mathrm{c}, 6 \mathrm{e}, \mathbf{6 g}$, and $\mathbf{6} \mathbf{i}-\mathbf{l}$ were quantitatively isolated (Supporting Information). In this regard, we continued our studies with $\mathbf{6 c}, \mathbf{6 g}$, and $\mathbf{6 i}$ derivatives.

C-Terminal Functionalization. As a drug model, several aliphatic and aromatic amines were successfully incorporated into the free C-terminal carboxylic acid using an excess of the soluble carbodiimide $(\mathrm{EDC} \cdot \mathrm{HCl})$ as the coupling agent, in the presence of Oxyma Pure as the additive, furnishing the corresponding amides in moderate to high yields after purification (Scheme 2). Of note, as the C-terminal lacks epimerizable $\alpha$-proton, the adducts will not undergo racemization.

$\mathrm{N}$-Terminal Functionalization. After removing $\mathrm{Cbz}$ or Fmoc from the Ugi adducts, amine functionalization is needed to anchor the amines present in the biomolecule. In this regard, a convenient approach to anchor the reactive amines of peptides and proteins is via amide bond formation. To this end, we functionalized the $\mathrm{N}$-terminal of our dipeptidic scaffolds.

As a first approach for the Cbz-protecting group, palladiumcatalyzed hydrogenolysis was done to yield the corresponding amines for further functionalization (see the Supporting Information). However, we detected diketopiperazine formation, which may hamper the reaction yield, so an alternative approach was developed. To avoid this side reaction, optimization was performed by a one-pot deprotection and acylation reaction. First, the $\mathrm{Cbz}$ hydrogenolysis was performed followed by in situ amine acylation using diglycolic anhydride (Scheme 2, reaction a). This strategy gave the desired derivatives $\mathbf{1 0 a}-\mathbf{d}$ in excellent yields and without further purification of the crude products (see the Supporting Information).

In the same manner, the Fmoc-protected dipeptides (8d and $8 \mathrm{e}$ ) were functionalized with the diglycolic moiety (Scheme 2, reaction $\mathrm{b}$ ). To this end, simultaneous elimination and acylation of the protecting group were attempted. For Fmoc substrates, the N-terminal protecting group was removed using a strong and non-nucleophilic base (DBU), and potassium fluoride and diglycolic anhydride were added to trap the amine released, thereby allowing simultaneous Fmoc elimination and amine acylation. Although the reaction yields were low compared with the $\mathrm{Cbz}$ analogs (see the Supporting Information), the use of the Fmoc group was crucial when the amine attached to the C-terminal was hydrogen-sensitive.

To determine the stability of these Ugi adducts, compound $10 \mathrm{~b}(1 \mathrm{mg} / \mathrm{mL})$ was incubated in male human serum type $A B$ 


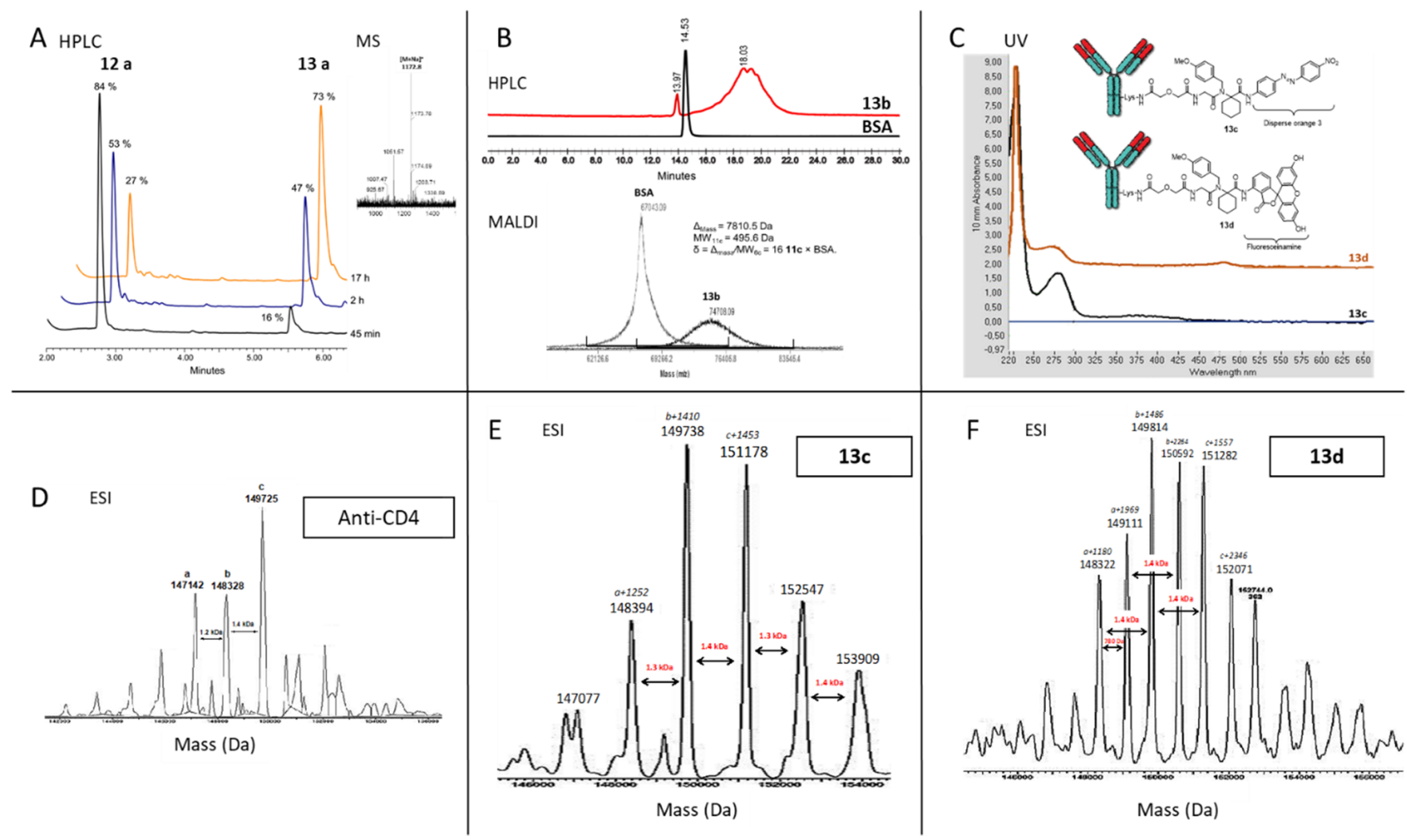

Figure 1. Conjugate characterization. (A) HPLC and HPLC-MS analysis of peptide 12a conjugation at $45 \mathrm{~min}, 2 \mathrm{~h}$, and $17 \mathrm{~h}$ reaction times. (B) HPLC and MALDI analysis of BSA and conjugate 13b. (C) UV spectra of 13c and 13d. (D-F) ESI-MS analysis for deglycosylated anti-CD4 and conjugates $13 \mathrm{c}$ and $13 \mathrm{~d}$, respectively.

and Hank's Balanced Salt solution (HBSS) $(9: 1)$ at $37^{\circ} \mathrm{C}$ for $24 \mathrm{~h}$. The reaction was monitored by HPLC from $30 \mathrm{~min}$ to 24 $\mathrm{h}$ of incubation. After $24 \mathrm{~h}$ of treatment, no evidence of degradation of compound $\mathbf{1 0 b}$ was found, thereby indicating the stability of the linker in human serum. Compounds 10a-c were also treated with a milder acidolytic aqueous mixture (MES $0.1 \mathrm{M}$ at $\mathrm{pH}=4.8$ ), and as expected, they did not undergo $\mathrm{C}$-terminal amide cleavage. This inherent stability supports that the tested Ugi adducts are suitable non-cleavable linkers for bioconjugation.

Bioconjugation. To achieve the bioconjugation through the $\varepsilon$-amino (lysine) or $\mathrm{N}$-terminal $\alpha$-amino groups of biomolecules, we activated the carboxylic acids $(\mathbf{1 0 a}-\mathbf{h})$ through $\mathrm{N}$-hydroxysuccinimide esterification (Scheme 2, reaction c). This was achieved by treating the free carboxylic acid with an equimolecular amount of HOSu and a slight excess of dicyclohexylcarbodiimide as the coupling agent in a mixture of AcOEt:dioxane (1:1) as the solvent. The solvent mixture caused the precipitation of dicyclohexyl urea and facilitated its elimination from the reaction crude product by filtration, quantitatively yielding the activated $\mathrm{HOSu}$ esters $(11 a-e)$.

With the activated $N$-hydroxysuccinic esters in hand (11ae), the bioconjugation to a peptide, a protein, and a monoclonal antibody was tackled. First, these esters were conjugated to a Lys-containing peptide. For this purpose, the pentapeptide $\mathrm{N}^{319} \mathrm{GKEY}^{323}$ (12a), selected from the heavy chain of the humanized IgG1 monoclonal antibody trastuzumab (anti-HER2), was manually synthesized by solid-phase peptide synthesis using the Fmoc/tBu strategy to yield the Nacetyl and C-amidated pentapeptide (see the Supporting
Information). The Lys conjugation was performed by adding the activated carboxylic acid (10 equiv.) in DMF (5\%) to a solution of the synthesized peptide in $\mathrm{PBS}$ at $\mathrm{pH}=7.4$ for $17 \mathrm{~h}$ at room temperature (Scheme 3A). HPLC and HPLC-MS analyses (Figure 1A) revealed the formation of conjugate 13a (73\% HPLC conversion).

After observing efficient lysine conjugation in a peptidic sequence, we moved on to address bioconjugation in a more complex system. For this purpose, we bound compound $11 \mathrm{c}$ to bovine serum albumin protein (BSA, 12b) (Scheme 3B). Analysis of the resulting BSA-conjugate $\mathbf{1 3 b}$ (Figure 1) showed, as expected for lysine-mediated ligation, a heterogeneous conjugation to the lysine of BSA (broad HPLC peak observed). Moreover, the conjugation was efficient. Mass analysis determined that 16 molecules of $11 \mathrm{c}$ were attached to the BSA surface when 1.7 equiv. of compound $11 \mathrm{c} \times$ one molecule of BSA (total 60 equiv.) were used. To test the stability of the conjugate, $13 \mathrm{~b}$ was treated with a MES $0.1 \mathrm{M}$ buffer at $\mathrm{pH}=4.8$ at $37^{\circ} \mathrm{C}$ for $24 \mathrm{~h}$. No appreciable hydrolysis was observed.

Going a step further, conjugation to anti-CD4, a monoclonal antibody (Scheme 3C), was performed. A solution of activated 11d (4 equiv.) and 11e ( 4 equiv.) in DMSO was added separately to a solution of anti-CD4 $(1.5$ and $1.0 \mathrm{mg} / \mathrm{mL}$ for $11 \mathrm{~d}$ and 11e, respectively) in PBS at $\mathrm{pH} 7.4$ and was left to react for $17 \mathrm{~h}$ at $4{ }^{\circ} \mathrm{C}$. The excess linker was then removed using a size-exclusion column, and the fractions obtained were characterized (Figure $1 \mathrm{C}-\mathrm{F}$ and Supporting Information). UV analysis of $13 \mathrm{c}$ and $13 \mathrm{~d}$ (Figure $1 \mathrm{C}$ ) revealed the variation of the UV spectra at 375 and $490 \mathrm{~nm}$, respectively, thereby confirming the conjugation. This finding indicates that the 
conjugated fluorophores were attached to the antibody. Using ESI-MS and after antibody deglycosylation with PNGase F, we detected at least two molecules of $11 \mathrm{c}$ and $11 \mathrm{~d}$ attached to the antibody.

Antibody Affinity Is Not Hampered by Conventional Amine Bioconjugation. To determine whether the conjugation of 11c and 11d to the anti-CD4 HP2/6 mAbs affected the binding to their epitopes, we performed an antibody binding analysis with the Jurkat cell line that constitutively expresses CD4 (Figure 2). We used increasing concentrations

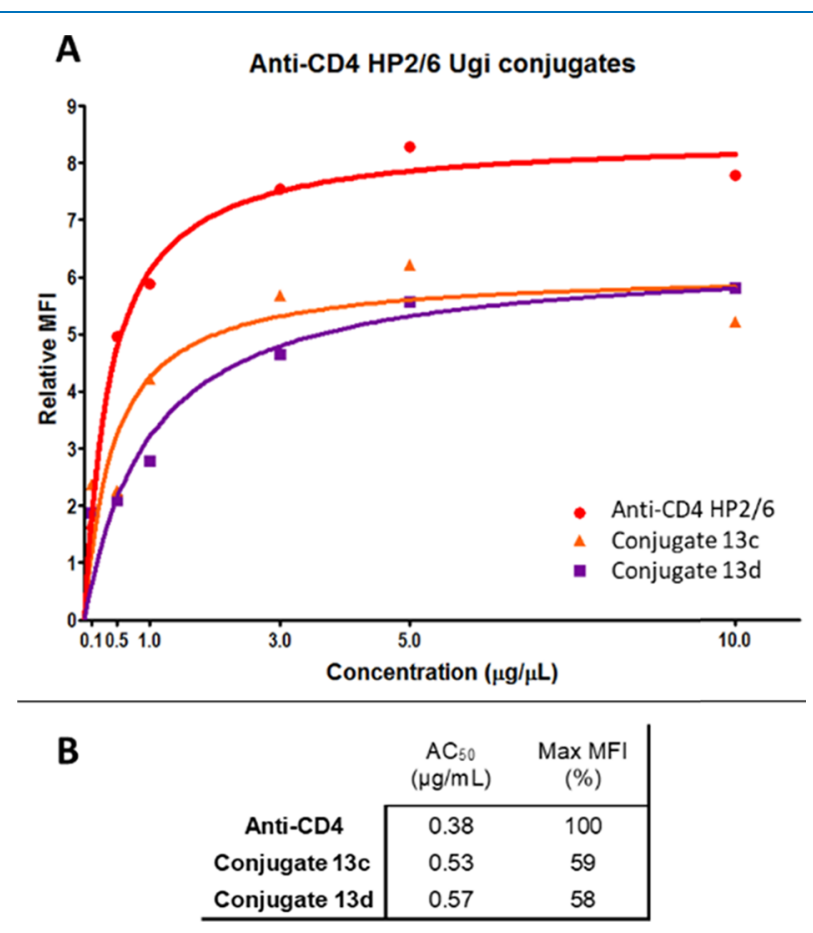

Figure 2. (A) Cell binding analysis by flow cytometry of anti-CD4 and conjugates $13 \mathrm{~d}$ and $13 \mathrm{c}$ to Jurkat cells. The cell line was incubated with the indicated concentrations of $\mathrm{mAb}$ or the conjugates $7 \mathrm{~d}$ and $7 \mathrm{c}$ followed by incubation with FITC-labeled goat anti-mouse IgG antibodies. The mean fluorescence intensity (MFI) ratio was calculated using the MFI value of an irrelevant mAb (basal MFI value) as reference. (B) $\mathrm{AC}_{50}$ and Max MFI (\%) for $\mathrm{mAb}$ anti-CD4 and its conjugates $(13 \mathrm{c}$ and $13 \mathrm{~d}) . \mathrm{AC}_{50}$, calculated as the antibody concentration (AC) needed to achieve $50 \%$ of the highest MFI value for each conjugate.

$(0.1-10 \mu \mathrm{g} / \mathrm{mL})$ of the naked antibody (anti-CD4 HP2/6 $\mathrm{mAbs}$ ) and its corresponding conjugates (13c and $13 \mathrm{~d}$ ). Accordingly, $13 \mathrm{c}$ and $\mathbf{1 3 d}$ were still active against CD4 with a slight reduction in binding affinity compared to the anti-CD4 $\mathrm{mAb}\left(\mathrm{AC}_{50} 0.53\right.$ and $0.57 \mu \mathrm{g} / \mathrm{mL}$ compared to $0.38 \mu \mathrm{g} / \mathrm{mL}$, respectively). This result suggests that $13 \mathrm{c}$ and $13 \mathrm{~d}$ coat more than $50 \%$ of all available CD4 molecules on the cell surface. This decrease in binding affinity could result from lysine conjugation, which may affect the antigen-binding site or even the constant region of the antibody, which the secondary antibody recognizes.

Anti-HER2 ADCs Linked with UGI Adducts Show Specific Targeting against HER2 ${ }^{+}$Cancer Cells. As a final step to validate these linkers in a biological setting, we conjugated an antitumoral tubulin-targeting payload with trastuzumab, a therapeutic antibody. The potential of the resulting $\mathrm{ADC}$ to inhibit cell growth was tested, as was its selectivity against tumor cells expressing the trastuzumab target, that is, the receptor tyrosine-protein kinase erbB-2, also known as HER2. The marine molecule PM050489, ${ }^{29}$ which binds tubulin with $\mathrm{pM}$ affinity and causes cell death with potencies in the same sub-nM, ${ }^{30}$ was used to generate the derivative PM120028, which was modified to incorporate the Ugi adduct decorated with a maleimide functionality to allow conjugation at $\mathrm{Cys}$ residues in trastuzumab.

The resulting ADC, named MI150011 (structure shown in Figure 3), was tested for its capacity to impair cell growth in four human breast cancer cell lines, namely, SK-BR-3 (HER2 positive), HCC-1954 (HER2 positive), MDA-MB-231 (HER2 negative), and MCF-7 (HER2 negative). MI50011 yielded $\mathrm{IC}_{50}$ values in the $\mathrm{nM}$ range against the HER2-positive lines, whereas its potency decreased around 1 order of magnitude against HER2-negative cells (Figure 3).

Although the potency of MI150011 was significantly lower than that of the initial PM120028 molecule, its greater activity in HER2-positive lines indicates a degree of selectivity that was absent in the latter. This selectivity demonstrates that MI150011 shows adequate stability in solution and that its conjugation to the antibody does not preclude the ability of the latter to interact with its antigen, hence validating the use of this linker for the preparation of novel therapeutic entities.

\section{CONCLUSIONS}

Here, we described an efficient strategy to synthesize and apply trialkylglycine derivatives (Ugi adducts) as linkers for bioconjugation. Correspondingly, a small library of $15 \mathrm{~N}$ alkylated $\alpha, \alpha$-dialkylglycines were synthesized in moderate to high yields by an Ugi multicomponent reaction and conveniently characterized. These adducts led to the Cterminal carboxylic group under TFA solutions in organic solvents. However, they are totally stable under low acidic conditions in aqueous media, thereby making them strong candidates as non-cleavable linkers for bioconjugation due to their intrinsic stability.

The demonstrated ease with which both the C- and Ntermini of the designed dipeptidic-based linkers can be selectively modified in different manners reveals an interesting versatile system with broad applicability in the field of bioconjugation. As shown, these linkers allow the introduction of distinct kinds of amines, as drug models, to the C-termini using standard coupling conditions. Even more interesting is that the lack of epimerizable $\alpha$-proton could allow the use of stronger coupling reagents. In addition, the reactive amino group at the N-termini could allow straightforward modification for further activation for conjugation. Here, we identified an interesting strategy involving the simultaneous elimination of the protecting group and acylation with a symmetric anhydride (one-pot reaction) that yielded a free carboxylic acid available for bioconjugation. All the reaction conditions were optimized to finally obtain high reaction yields and purity of the crude products.

Furthermore, we found that mild conjugation strategies for amine and cysteine amino acids through different biomolecules were successful and did not affect the integrity or properties of the biomolecules. Despite the conjugation process, the ADCs synthesized did not lose their ability to bind to CD4 in Jurkat cells in comparison to the naked antibody. Going one step further, we prepared a novel cytotoxic anti-HER2 ADC using one of the Ugi linkers described herein. The cell viability studies with this ADC showed specificity toward HER2- 
A

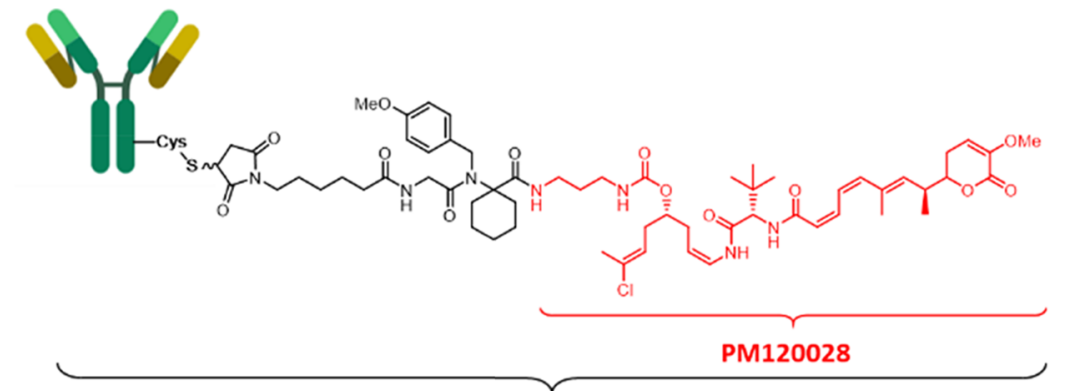

MI150011

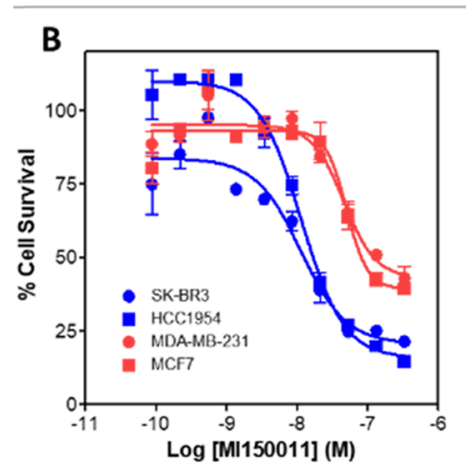

C

\begin{tabular}{cccc}
\hline \multirow{2}{*}{ Cell line } & HER2 status & \multicolumn{2}{c}{ IC $_{\text {50 }}(\mathrm{nM})$} \\
\cline { 2 - 4 } & & Ml150011 & PM120028 \\
\hline SK-BR-3 & Positive & 12.7 & 0.3 \\
\cline { 2 - 4 } HCC-1954 & Positive & 17.3 & 0.5 \\
\cline { 2 - 4 } MDA-MB-231 & Negative & 120 & 0.9 \\
\cline { 2 - 4 } MCF-7 & Negative & 80 & 0.8 \\
\hline
\end{tabular}

Figure 3. (A) Structure of the ADC MI150011 and the initial molecule PM120028. (B) Dose-response curves showing the effect of MI150011 on cell survival after $72 \mathrm{~h}$ of incubation with breast cancer cell lines. Error bars correspond to the standard deviation of triplicate samples. $(\mathrm{C}) \mathrm{IC}_{50}$ values for MI150011 and PM120028 in cell lines with different HER2 expression levels.

positive cell lines, thereby confirming the utility of Ugi adducts to prepare new linkers for conjugation.

\section{EXPERIMENTAL SECTION}

Ugi Multicomponent Reaction. The corresponding ketone ( 1 equiv. or excess) and the primary amine (1 equiv.) were mixed for $15 \mathrm{~min}$ at room temperature in the presence of $\mathrm{Na}_{2} \mathrm{SO}_{4}$. Liquid ketones were used as a reaction solvent. For high-boiling-point or solid ketones, $2 \mathrm{~mL}$ of $\mathrm{MeOH}$ was added to the reaction. Then $\mathrm{N}$-protected amino acid ( 1 equiv.) was added, and the mixture was stirred for 10 min. After that, cyclohexyl isocyanide (1 equiv.) was added to the mixture, which was left to react for $1 \mathrm{~h}$ to $2-3$ weeks, depending on the progression of the reaction, at room temperature and in the dark to avoid side reactions. The suspension was then filtered, and the solvent was removed under vacuum. Finally, the crude was purified through chromatographic techniques or by recrystallization to obtain the final product with adequate purity. All starting amines were commercially available, except $4-\mathrm{MeO}_{-} \mathrm{PEG}_{9}$-benzylamine (2k), which was previously prepared by the ether formation between 4-cyanophenol and the bromo-PEGylated derivative followed by nitrile reduction to yield 4-MeO-PEG 9 -benzylamine (two steps, 58\%, see the Supporting Information).

Acidolysis of Ugi Adducts. The protected amides 5a-o $(1 \mathrm{mg} / \mathrm{mL}$ in $\mathrm{MeCN})$ were treated with $0.1-1 \%$ TFA solutions. Some molecules needed mixtures of $0.1-1 \%$ TFA in $\mathrm{H}_{2} \mathrm{O} / \mathrm{MeCN}$ (1:1) (see the Supporting Information).

C-Terminal Functionalization. The free C-terminal carboxylic acid dipeptide (1 equiv.) was treated with the corresponding amine ( 1 to 5 equiv.) using $\mathrm{EDC} \cdot \mathrm{HCl}$ (from 1 equiv. to excess) as the coupling reagent and Oxyma Pure ( 1 to 9 equiv.) as an additive in $\mathrm{MeCN}$ or DMF as the solvent. The reaction led to carboxylic consumption, as monitored by
HPLC. The solvent was removed under reduced pressure. The solid was dissolved in AcOEt $(25 \mathrm{~mL})$, and the organic layer was washed with water $(3 \times 20 \mathrm{~mL})$, saturated $\mathrm{Na}_{2} \mathrm{CO}_{3}(3 \times$ $20 \mathrm{~mL})$, and brine $(3 \times 20 \mathrm{~mL})$ and dried over $\mathrm{MgSO}_{4}$, and the solvent was then removed. When needed, the final product was isolated by automatic purification on a prepacked Redisep Rf Gold $\mathrm{C}_{18} 13 \mathrm{~g}$ column by using $\mathrm{H}_{2} \mathrm{O} / \mathrm{MeCN}$ from 90:10 to $0: 100$ over $20 \mathrm{~min}$. The collected fractions were lyophilized to yield $8 \mathbf{a}-\mathbf{e}$.

One-Pot Protecting Group Removal and Amine Acylation. Cbz: The Cbz-protected dipeptide $(5 \mathrm{~d}, 5 \mathrm{~g}, 5 \mathrm{~m}$, or $\mathbf{8} \mathbf{a}-\mathbf{c})$ was dissolved in dry THF. Diglycolic anhydride (1 equiv.) and $\mathrm{Pd} / \mathrm{C}$ catalyst (10\% weight) were then added, and the system was purged with $\mathrm{N}_{2}$ and $\mathrm{H}_{2}$. The reaction was stirred under a $\mathrm{H}_{2}$ atmosphere at room temperature until complete $\mathrm{Cbz}$ elimination. The reaction was followed by HPLC. The solution was filtered over Celite, and the solvent was removed under reduced pressure to yield the $\mathrm{N}$-terminal acylated dipeptides.

Fmoc: The Fmoc-protected compound $\mathbf{8 d}$ or $\mathbf{8 e}$ (1 equiv.) in DMF, diglycolic anhydride (1 equiv.), KF supported on $\mathrm{Al}_{2} \mathrm{O}_{3}$ (3 equiv.), and $\mathrm{DBU}$ (1.2 equiv.) were added, and the mixture was stirred under a $\mathrm{N}_{2}$ atmosphere until complete Fmoc elimination. The mixture was then filtered, and the solvent was removed under reduced pressure. The crude was purified on a prepacked Redisep Rf Gold $\mathrm{C}_{18} 13 \mathrm{~g}$ column using $\mathrm{H}_{2} \mathrm{O} / \mathrm{MeCN}$ from 90:10 to 0:100 over 20 min. The fractions were collected and lyophilized obtaining the $\mathrm{N}$-acylated compound $10 \mathrm{~g}$ or $10 \mathrm{~h}$.

HOSu Activation. A solution of the corresponding carboxylic acid $(\mathbf{1 0 a}-\mathbf{f})$ in dioxane/AcOEt $(1: 1)$ was treated with $N$-hydroxysuccinimide (1-2 equiv.) and DCC (1-2 equiv.). The reaction was stopped when the starting $\mathrm{COOH}$ disappeared (HPLC). The solution was filtered over Celite and 
then passed through a $0.2 \mu \mathrm{m}$ filter. The solvent was removed under reduced pressure. The products were used for conjugation without further purification.

Bioconjugation. A solution of the activated OSu esters $11 a-e$ (1.5-60 equiv. per lysine in the biomolecule) in DMF/ DMSO (2-10\%) was added to a biomolecule-containing solution $(0.5-11 \mathrm{mg} / \mathrm{mL})$ in PBS $(\mathrm{pH}=7.4)$. The mixture was left to react for 17-24 h. The excess unreacted molecules were then removed by PD-10 desalting column purification using water as the eluent. Next, the protein-containing fractions were collected and characterized.

Binding Affinity Experiments. Jurkat $\left(5 \times 10^{5}\right)$ cells were first incubated with $50 \mu \mathrm{g} / \mathrm{mL} \gamma$-globulin for $10 \mathrm{~min}$ and then with the anti-CD4 HP2/6 monoclonal antibody (mAb) or the corresponding conjugates at the indicated concentrations for $1 \mathrm{~h}$ on ice. Cells were then washed with PBS twice and incubated with $10 \mu \mathrm{g} / \mathrm{mL}$ FITC-labeled goat anti-mouse IgG antibodies (BD Biosciences) for $30 \mathrm{~min}$ on ice. Finally, they were washed twice and resuspended in PBS for their analysis by flow cytometry using a FACSCanto II cytometer.

\section{ASSOCIATED CONTENT}

\section{SI Supporting Information}

The Supporting Information is available free of charge at https://pubs.acs.org/doi/10.1021/acsomega.0c00099.

Synthetic and analytical details (methodologies, HPLC, NMR, UV-vis, ESI-MS, and SDS-PAGE) (PDF)

\section{AUTHOR INFORMATION}

\section{Corresponding Authors}

Hortensia Rodríguez - Institute for Research in Biomedicine, 08028 Barcelona, Spain; School of Chemical Sciences and Engineering, Yachay Tech University, Yachay City of Knowledge, 100650 Urcuqui, Ecuador; Phone: + 593-994-336-513; Email: hmrodriguez@yachaytech.edu.ec

Fernando Albericio - Institute for Research in Biomedicine, 08028 Barcelona, Spain; Department of Organic Chemistry, University of Barcelona, 08028 Barcelona, Spain; CIBER-BBN, Networking Centre on Bioengineering, Biomaterials and Nanomedicine, 08028 Barcelona, Spain; School of Chemistry, University of KwaZulu-Natal, 4001 Durban, South Africa; (1) orcid.org/0000-0002-8946-0462; Phone: +34-618-089145; Email: albericio@ub.edu

\section{Authors}

Iván Ramos-Tomillero - Institute for Research in Biomedicine, 08028 Barcelona, Spain; Department of Organic Chemistry, University of Barcelona, 08028 Barcelona, Spain; (1) orcid.org/ 0000-0003-1928-4149

Gema Pérez-Chacon - Instituto de Investigaciones Biomédicas "Alberto Sols", CSIC-UAM, 28029 Madrid, Spain,

Beatriz Somovilla-Crespo - Servicio de Inmunologia, Instituto de Investigación Sanitaria Hospital de la Princesa, 28006 Madrid, Spain

Francisco Sánchez-Madrid - Servicio de Inmunologia, Instituto de Investigación Sanitaria Hospital de la Princesa, 28006 Madrid, Spain

Carmen Cuevas - Research Department, PharmaMar S.A., 28770 Madrid, Spain

Juan Manuel Zapata - Instituto de Investigaciones Biomédicas "Alberto Sols", CSIC-UAM, 28029 Madrid, Spain
Juan Manuel Domínguez - Research Department, PharmaMar S.A., 28770 Madrid, Spain

Complete contact information is available at:

https://pubs.acs.org/10.1021/acsomega.0c00099

\section{Author Contributions}

I.R.-T. did the experimental synthesis of Ugi adducts and bioconjugation and data analysis. G.P.-C., B.S.-C., F.S.-M., and J.M.Z performed binding affinity experiments and data analyses of the results. C.C. and J.M.D. did the synthesis and data analysis of the ADC MI150011 and its component molecule PM120028. I.R.-T, H.R., and F.A. wrote the paper with contribution and revision of all the other authors and designed the experiments. H.R. and F.A. supervised the project. F.A., C.C., J.M.Z., and F.S.-M. conceived the project MarinMab.

Notes

The authors declare no competing financial interest.

\section{ACKNOWLEDGMENTS}

I.R-T. thanks the Generalitat de Catalunya for a predoctoral fellowship. This work was funded in part by the following: the Ministerio de Economía y Competitividad [Programa INNPACTO, project MarinMab (IPT-2012-0198-090000) and RTI2018-093831-B-100], the Generalitat de Catalunya (2017SGR-1439), and the Institute for Research in Biomedicine Barcelona (IRB Barcelona) (Spain); National Research Foundation (Blue Skies, \# 120386) (South Africa); and Yachay Tech (Ecuador). The authors thank the Mass Spectrometry and Proteomics Core Facility of IRB Barcelona for their support with conjugate analysis.

\section{ABBREVIATIONS}

ADC, antibody-drug conjugate; Mmt, 4-monomethoxytrityl; Fmoc, 9-fluorenylmethoxycarbonyl; Cbz, carboxybenzyl; cHx, cyclohexyl

\section{REFERENCES}

(1) Hermanson, G. T. Bioconjugate Techniques; 2nd ed.; Elsiever Inc.: 2008; Vol. 28.

(2) Van Hest, J.; Sumerlin, B.; Anseth, K. S.; Shoichet, M.; HammesSchiffer, S. Editorial for Virtual Issue on Polymer Bioconjugates in Biology and Medicine. ACS Macro Lett. 2017, 6, 144.

(3) Hess, C.; Venetz, D.; Neri, D. Emerging Classes of Armed Antibody Therapeutics against Cancer. Medchemcomm 2014, 5, 408.

(4) Panowski, S.; Bhakta, S.; Raab, H.; Polakis, P.; Junutula, J. R. Site-Specific Antibody Drug Conjugates for Cancer Therapy. mAbs 2013, 6, 34-45.

(5) Lyon, R. P.; Meyer, D. L.; Setter, J. R.; Senter, P. D. Conjugation of Anticancer Drugs through Endogenous Monoclonal Antibody Cysteine Residues. Methods Enzymol. 2012, 502, 123-138.

(6) Ballantyne, A.; Dhillon, S. Trastuzumab Emtansine: First Global Approval. Drugs 2013, 73, 755-765.

(7) Lamb, Y. N. Inotuzumab Ozogamicin: First Global Approval. Drugs 2017, 77, 1603-1610.

(8) Jen, E. Y.; Ko, C.-W.; Lee, J. E.; Del Valle, P. L.; Aydanian, A.; Jewell, C.; Norsworthy, K. J.; Przepiorka, D.; Nie, L.; Liu, J.; et al. FDA Approval: Gemtuzumab Ozogamicin for the Treatment of Adults with Newly Diagnosed CD33-Positive Acute Myeloid Leukemia. Clin. Cancer Res. 2018, 3242.

(9) Albers, A. E.; Garofalo, A. W.; Drake, P. M.; Kudirka, R.; de Hart, G. W.; Barfield, R. M.; Baker, J.; Banas, S.; Rabuka, D. Exploring the Effects of Linker Composition on Site-Specifically Modified Antibody-Drug Conjugates. Eur. J. Med. Chem. 2014, 88, 3-9. 
(10) Shamay, Y.; Adar, L.; Ashkenasy, G.; David, A. Light Induced Drug Delivery into Cancer Cells. Biomaterials 2011, 32, 1377-1386.

(11) Kellogg, B. A.; Garrett, L.; Kovtun, Y.; Lai, K. C.; Leece, B.; Miller, M.; Payne, G.; Steeves, R.; Whiteman, K. R.; Widdison, W.; et al. Disulfide-Linked Antibody-Maytansinoid Conjugates: Optimization of in Vivo Activity by Varying the Steric Hindrance at Carbon Atoms Adjacent to the Disulfide Linkage. Bioconjugate Chem. 2011, 22, 717-727.

(12) Doronina, S. O.; Toki, B. E.; Torgov, M. Y.; Mendelsohn, B. A.; Cerveny, C. G.; Chace, D. F.; DeBlanc, R. L.; Gearing, R. P.; Bovee, T. D.; Siegall, C. B.; et al. Development of Potent Monoclonal Antibody Auristatin Conjugates for Cancer Therapy. Nat. Biotechnol. 2003, 21, 778-784.

(13) Jain, N.; Smith, S. W.; Ghone, S.; Tomczuk, B. Current ADC Linker Chemistry. Pharm. Res. 2015, 32, 3526-3540.

(14) Erickson, H. K.; Park, P. U.; Widdison, W. C.; Kovtun, Y. V.; Garrett, L. M.; Hoffman, K.; Lutz, R. J.; Goldmacher, V. S.; Blättler, W. A. Antibody-Maytansinoid Conjugates Are Activated in Targeted Cancer Cells by Lysosomal Degradation and Linker-Dependent Intracellular Processing. Cancer Res. 2006, 66, 4426-4433.

(15) Lambert, J. M.; Chari, R. V. J. Ado-Trastuzumab Emtansine (TDM1): An Antibody-Drug Conjugate (ADC) for HER2-Positive Breast Cancer. J. Med. Chem. 2014, 57, 6949-6964.

(16) Buskas, T.; Li, Y.; Boons, G.-J. The Immunogenicity of the Tumor-Associated Antigen Lewisy May Be Suppressed by a Bifunctional Cross-Linker Required for Coupling to a Carrier Protein. Chem. - Eur. J. 2004, 10, 3517-3524.

(17) Dömling, A.; Ugi, I. Multicomponent Reactions with Isocyanides. Angew. Chem., Int. Ed. 2000, 39, 3168-3210.

(18) Ziegler, T.; Gerling, S.; Lang, M. Preparation of Bioconjugates through an Ugi Reaction. Angew. Chem., Int. Ed. 2000, 39, 21092112.

(19) Icart, L. P.; dos Santos, E. R. F.; Pereira, E. D.; Ferreira, S. R.; Saez, V.; Ramon, J. A.; Nele, M.; Pinto, J. C. S.; Toledo, R. D.; Silva, D. Z.; et al. PLA-b-PEG/Magnetite Hyperthermic Agent Prepared by Ugi Four Component Condensation. Express Polym. Lett. 2016, 10, 188-203.

(20) Nenajdenko, V. G.; Gulevich, A. V.; Sokolova, N. V.; Mironov, A. V.; Balenkova, E. S. Chiral Isocyanoazides: Efficient Bifunctional Reagents for Bioconjugation. Eur. J. Org. Chem. 2010, 2010, 14451449.

(21) Méndez, Y.; Chang, J.; Humpierre, A. R.; Zanuy, A.; Garrido, R.; Vasco, A. V.; Pedroso, J.; Santana, D.; Rodríguez, L. M.; GarcíaRivera, D.; Valdés, Y.; Vérez-Bencomo, V.; Rivera, D. G. Multicomponent Polysaccharide-Protein Bioconjugation in the Development. of Antibacterial Glycoconjugate Vaccine Candidates. Chem. Sci. 2018, 9, 2581-2588.

(22) Slobbe, P.; Ruijter, E.; Orru, R. V. A. Recent applications of multicomponent reactions in medicinal chemistry. Med. Chem. Commun. 2012, 3, 1189-1218.

(23) Zarganes-Tzitzikas, T.; Chandgude, A. L.; Dömling, A. Multicomponent Reactions, Union of MCRs and Beyond. The Chemical Record. 2015, 15, 981-996.

(24) Rocha, R. O.; Rodrigues, M. O.; Neto, B. A. D. Review on the Ugi Multicomponent Reaction Mechanism and the Use of Fluorescent Derivatives as Functional Chromophores. ACS Omega. 2020, 5, 972-979.

(25) Brauch, S.; Henze, M.; Osswald, B.; Naumann, K.; Wessjohann, L. A.; van Berkel, S. S.; Westermann, B. Fast and efficient MCR-based synthesis of clickable rhodamine tags for protein profiling. Org. Biomol. Chem. 2012, 10, 958-965.

(26) Yang, B.; Zhao, Y.; Wang, S.; Zhang, Y.; Fu, C.; Wei, Y.; Tao, L. Synthesis of Multifunctional Polymers through the Ugi Reaction for Protein Conjugation. Macromolecules 2014, 47, 5607-5612.

(27) Vasco, A. V.; Méndez, Y.; Porzel, A.; Balbach, J.; Wessjohann, L. A.; Rivera, D. G. A Multicomponent Stapling Approach to Exocyclic Functionalized Helical Peptides: Adding Lipids, Sugars, PEGs, Labels, and Handles to the Lactam Bridge. Bioconjugate Chem 2018, 30, 253-259.
(28) Reguera, L.; Méndez, Y.; Humpierre, A. R.; Valdés, O.; Rivera, D. G. Multicomponent Reactions in Ligation and Bioconjugation Chemistry. Acc. Chem. Res. 2018, 51, 1475-1486.

(29) Martín, M. J.; Coello, L.; Fernández, R.; Reyes, F.; Rodríguez, A.; Murcia, C.; Garranzo, M.; Mateo, C.; Sánchez-Sancho, F.; Bueno, S.; et al. Isolation and First Total Synthesis of PM050489 and PM060184, Two New Marine Anticancer Compounds. J. Am. Chem. Soc. 2013, 135, 10164-10171.

(30) Pera, B.; Barasoain, I.; Pantazopoulou, A.; Canales, A.; Matesanz, R.; Rodriguez-Salarichs, J.; García-Fernandez, L. F.; Moneo, V.; Jiménez-Barbero, J.; Galmarini, C. M.; et al. New Interfacial Microtubule Inhibitors of Marine Origin, PM050489/ PM060184, with Potent Antitumor Activity and a Distinct Mechanism. ACS Chem. Biol. 2013, 8, 2084-2094. 